\title{
Degradation of Imidacloprid Residue on Red Tomatoes (Solanum lycopersicum) by Advanced Oxidation Processes and Analysis using Spectrophotometer and HPLC
}

\author{
Safni Safni ${ }^{*}$, Hazanita Jumiaty ${ }^{1}$, Hermansyah Aziz ${ }^{2}$ \\ ${ }^{1}$ Laboratory of Applied Analytical-Chemistry, Andalas University, Padang, West Sumatra, 25163, Indonesia \\ ${ }^{2}$ Laboratory of Physical Chemistry, Andalas University, Padang, West Sumatra, 25163, Indonesia \\ ${ }^{*}$ Corresponding author: safni@sci.unand.ac.id
}

Received: July 2021; Revision: September 2021; Accepted: November 2021; Available online: November 2021

\begin{abstract}
The insecticide imidacloprid $\left(\mathrm{C}_{9} \mathrm{H}_{10} \mathrm{ClN}_{5} \mathrm{O}_{2}\right)$ common used by farmers to control pests on red tomato plants, is a dangerous substance classified as a Class II toxic. The imidacloprid residue in red tomatoes enters the body, it will lead to health problems. The purpose of this study was to determine the percentage of imidacloprid residue that can be degraded using the Advanced Oxidation Processes (AOPs) method, which includes sonolysis, sonozolysis, ozonolysis, ozone water, and the effect of various parameters. Processing time, water volume, and red tomato mass were the test parameters studied. The change in imidacloprid residue concentration during the degradation process was measured using a UV/Vis spectrophotometer (double beam) with a wavelength of 200$400 \mathrm{~nm}$ and HPLC with mobile phase composition used was acetonitrile/water $(65: 35 \mathrm{v} / \mathrm{v})$. With a processing time of 10 minutes, the imidacloprid residue in red tomatoes can be degraded $57.38 \%$ by sonozonolysis, $63.51 \%$ by sonolysis, $85.17 \%$ by ozonolysis, and $88.76 \%$ by ozone water. The imidacloprid residue in $75 \mathrm{~g}$ of red tomatoes could be removed as much as $91.65 \%$ by treating with ozone water for 15 minutes. HPLC analysis showed that no intermediate compounds were detected in the imidacloprid residue degradation process in red tomatoes.
\end{abstract}

Keywords: AOPs, degradation, imidacloprid, ozone water, red tomatoes.

DOI: $10.15408 / j k v . v 7 i 2.21630$

\section{INTRODUCTION}

Imidacloprid $\left(\mathrm{C}_{9} \mathrm{H}_{10} \mathrm{ClN}_{5} \mathrm{O}_{2}\right)$ is a neonicotinoid insecticide that is effective against a wide variety of plant pests (Sharma $e t$ al., 2017). Imidacloprid is found to be widely used for a variety of agricultural including corn, potato, rice, and tomato (Morrissey et al., 2015). Imidacloprid's long-term consumption will have a significant effect on human health, because this insecticide is toxic and has a small molecular size, which when consumed will cause neurological diseases, reproductive problems, poisoning, kidney failure, and death due to pesticide residues left on vegetables (Dhananjayan \& Ravichandran, 2018) (Han et al., 2018). Pesticide residues in agricultural products have been removed with conventional methods by washing, peeling the skin, boiling, and heating (Lozowicka \& Jankowska, 2016). However, washing with ordinary water has limitations because it can only remove dirt that sticks to the surface of vegetables and will produce new waste in the water, rendering it ineffective in removing pesticide residues that have remained on the vegetables (Pinheiro et al., 2014) (Qi et al., 2017). Several studies on removing pesticide residues on vegetables have been conducted, including hydrostatic pressure (Iizuka et al., 2013), which uses various types of harmful organic solvents to degrade pesticides on cherry tomatoes, and electrolyzed water treatments (Hao et al., 2011) which use chemical substances to produce less effective and uneconomical results.

As a result, alternative methods to resolving problems in conventional methods are needed. Advanced Oxidation Processes (AOPs) are modern methods that can break down organic compounds into simpler molecules, this approach uses hydroxyl 
radicals $(\mathrm{OH} \bullet)$ as an oxidizing agent that include photolysis (used chemical reaction where a chemical compound is broken by photons or light energy), ozonolysis (used organic chemical reaction where ozone/ $\mathrm{O}_{3}$ is employed to cleave the unsaturated bonds), and sonolysis (where used ultrasonic waves). This method which has previously been successful to degrade organic compounds such as the pesticides diazinon, dyes (Safni Safni et al., 2020), phenol (Safni Safni et al., 2019), paracetamol (Safni Safni et al., 2017), and rhodamine B and acid red 14 binary solutions with homogeneous Fenton reaction (Aliasgharlou et al., 2020). Moreover, this method has several advantages, such as a low cost, a short amount of time needed, and the ability to produce environmentally friendly compounds. Based on the reviewed literature, the research was conducted treatment to reduce pesticide residues left in red tomatoes by AOPs, which included ozonolysis, sonolysis, sonozolysis (combined $\mathrm{O}_{3}$ and ultrasonic wave), and ozone water with a range of parameters. After that, the filtrate from those who have been treated vegetables was analyzed using a UV/VIS Spectrophotometer and High-Performance Liquid Chromatography (HPLC).

\section{MATERIALS AND METHODS Materials}

This study was carried out in Andalas University's Applied Analytical-Chemistry Laboratory. The imidacloprid used by Klopindo $10 \mathrm{WP}$, acetonitrile (HPLC Grade), aquadest, and filter paper. Red tomatoes were taken randomly from Agricultural Land in Aia Angek, Sepuluh Koto, Padang Panjang City, West Sumatera. The instrumentation used this research is ozone reactor (Hanaco X-troy CHS212, $15 \mathrm{~W}$ ), ultrasonic cleaner (Krisbow, 40 $\mathrm{kHz}$ ), Spectrophotometer (Shimadzu Corp, serial A116352, Japan), and HPLC (Agilent Technologies 1200).

\section{Procedure}

Degradation of Imidacloprid Residues in Red Tomatoes

\section{Effect of various methods of AOPs}

A red tomatoes sample was divided into four parts and homogenized. The sample taken with weight 75 grams, then $150 \mathrm{~mL}$ of water was added and placed in a beaker. For 10 minutes, the sample was flooded with ozone gas generated by the ozone reactor (sterilizer ozone producer). After the red tomatoes were degraded, crushed, then added $150 \mathrm{~mL}$ of water and filtered using filter paper. A UV/VIS Spectrophotometer was used to measure the absorbance of the filtrate at a wavelength of $270 \mathrm{~nm}$ (Niaz et al., 2016). The sonolysis, sonozolysis (combined sonolysis and ozonolysis), and ozone water procedures were all tested in the same way. Where sonolysis method used ultrasonic cleaner with a frequency of $40 \mathrm{kHz}$. The sonozolysis method is a combination of sonolysis (used ultrasonic cleaner with a frequency of $40 \mathrm{kHz}$ ) and ozonolysis (used ozone gas generated by the ozone reactor, sterilizer ozone producer) which are used together. For ozone water method, water was flooded with ozone gas generated by the ozone reactor without samples, after that red tomatoes soaked in water that has been in ozone.

\section{Effect of Processing Times}

A red tomatoes sample was divided into four parts and homogenized. The sample is taken with the weight of 50 grams, then 100 $\mathrm{mL}$ of water was added and placed in a beaker. The samples and water in a beaker were flooded with ozone gas generated by the ozone reactor (sterilizer ozone producer) with processing times $5,10,15,20$, and 25 minutes. The red tomatoes are crushed after being degraded, and $100 \mathrm{~mL}$ of water is added before filtering with filter paper. The absorption of the filtrate was then measured using a UV/VIS Spectrophotometer at a wavelength of $270 \mathrm{~nm}$.

\section{Effect of Water Volume}

A red tomatoes sample was divided into four parts and homogenized. The sample is taken with the weight of 50 grams, after that, water was added in increments of 50, 100, 150, and $200 \mathrm{~mL}$ ad placed in a beaker. For 10 minutes, the samples and water in a beaker flowed from the ozone reactor to produce ozone gas (sterilizer ozone producer). The red tomatoes are crushed after being degraded, then added with water according to the volume of water, and filtered with filter paper. The absorption of the filtrate was then measured using a UV/VIS Spectrophotometer at a wavelength of $270 \mathrm{~nm}$. 


\section{Effect on Vegetable Mass}

A red tomatoes sample was divided into four parts and homogenized. The sample is taken with variations of 50, 75, and 100 grams. Then $150 \mathrm{~mL}$ of water was added and placed in a beaker. For 10 minutes, the sample and water in a beaker were flooded flowed from the ozone reactor produces ozone gas (sterilizer ozone producer). The red tomatoes are crushed after being degraded, then mixed with $150 \mathrm{~mL}$ of water and filtered through filter paper. The absorption of the filtrate was then measured using a UV/VIS Spectrophotometer at a wavelength of $270 \mathrm{~nm}$.

\section{The Effect of Soaking Time with Ozone Water}

Water without a sample of $150 \mathrm{~mL}$ was flooded flowed from the ozone reactor produces ozone gas (sterilizer ozone producer) for 10 minutes. After that red tomatoes were soaked in water that has been in ozone with variations soaking times of $5,10,15,20$, and 25 minutes. The red tomatoes are crushed after being degraded, then add $150 \mathrm{~mL}$ of water and filter using filter paper. UV/VIS Spectrophotometer was used to measure the absorbance of the filtrate at a wavelength of $270 \mathrm{~nm}$.

\section{HPLC Analysis}

Reverse-phase HPLC with an UV detector at a wavelength of $270 \mathrm{~nm}$ was used to analyzed imidacloprid solutions and residual solutions before and after the degradation of red tomatoes. Reverse-phase HPLC equipped with a $\mathrm{C}_{18}$ column $(250 \mathrm{~mm} \times 4.6 \mathrm{~mm})$. The mobile phase for the analysis of the imidacloprid solution in red tomatoes was acetonitrile and water $(65: 35 \mathrm{v} / \mathrm{v})$, with a flow rate of $0.8 \mathrm{~mL} / \mathrm{min}$ and a $10 \mu \mathrm{L}$ injection volume.

\section{RESULTS AND DISCUSSION Imidacloprid residue degradation in red tomatoes \\ The effect of different methods of AOPs}

The ozonolysis method, which uses an ozone reactor (sterilizer ozone producer) with a $400 \mathrm{mg} /$ hour ozone capacity, was used where the ozone molecule reacts directly with vegetables containing pesticide residue; in the sonolysis method, an ultrasonic cleaner with a frequency of $40 \mathrm{kHz}$ is used; in the sonozolysis method, the sonolysis and ozonolysis methods are used simultaneously; and in the ozone water method, $\mathrm{O}_{3}$ is discharged from the ozone reactor into the water. Figure 1 shows that utilizing the ozone water approach, vegetable samples may be degraded effectively, as indicated by the $88.76 \%$ degradation value achieved for red tomatoes. The ozone water approach delivers the highest percentage because it involves an indirect reaction involving $\mathrm{OH} \bullet$, in which ozone $\left(\mathrm{O}_{3}\right)$ is injected into the water and reacts in an aqueous solution to generate a two-fold action of ozone and $\mathrm{OH} \bullet$, which is more effective. The reaction can be seen in the equation below (Gardoni et al., 2012):

$$
\begin{array}{lll}
\mathrm{OH}^{-}+\mathrm{O}_{3} & \rightarrow & \mathrm{HO}_{4}^{-} \\
\mathrm{HO}_{4}^{-} & \rightleftharpoons & \cdot \mathrm{HO}_{2}+\mathrm{O}_{2}^{--} \\
\mathrm{O}_{2}^{-{ }^{-}}+\mathrm{O}_{3} & \rightarrow & \mathrm{O}_{2}+\mathrm{O}_{3}^{-{ }^{-}} \\
\mathrm{O}_{3}^{\cdot-} & \rightarrow & \mathrm{O}_{2}+\cdot{ }^{-} \\
\cdot \mathrm{O}^{--}+\mathrm{H}_{2} \mathrm{O} & \rightarrow & \cdot \mathrm{OH}+\mathrm{OH}^{-}
\end{array}
$$

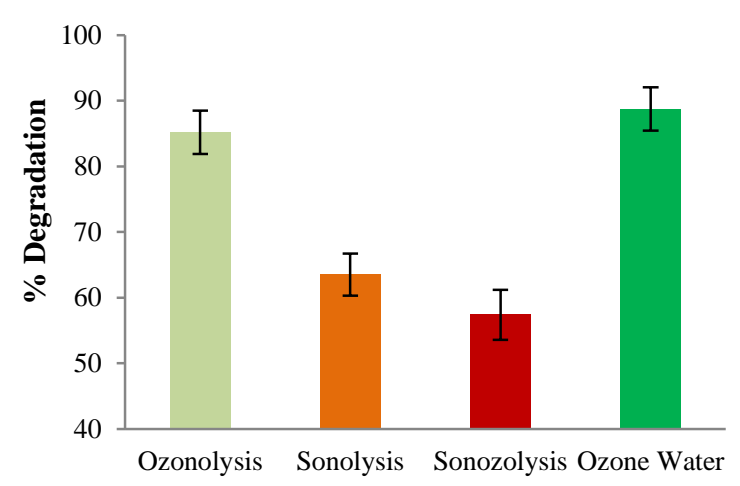

Figure 1. Effect of various methods of AOPs on the degradation of imidacloprid residues in red tomatoes

\section{The Effect of Processing Times}

To degrade imidacloprid residues in red tomatoes, the ozonolysis method was used with processing time variations of $5,10,15$, 20 , and 25 minutes, mass of red tomatoes $50 \mathrm{~g}$, and water volumes $100 \mathrm{~mL}$. Figure 2 shows that the higher the percentage of deterioration acquired with increasing time, the higher the percentage of deterioration acquired. This is because when time is added to ozonolysis, ozone $\left(\mathrm{O}_{3}\right)$ is produced, which can react with aqueous solutions directly or indirectly to create $\mathrm{OH} \bullet$ and disrupt chemical bonds. The longer the processing time, the more hydroxyl radicals were formed (Putri et al., 2019). Furthermore, because most red tomatoes have 
a thin skin (pericarp) and a bigger surface area to interact well with ozone, the optimum time attained in the degradation of pesticide residues on red tomato vegetables is faster, which is 10 minutes, reaching the optimal point $\left(\mathrm{O}_{3}\right)$. As a result, ozone $\left(\mathrm{O}_{3}\right)$ is very certainly present on the surface of these plants (Ikeura et al., 2011).

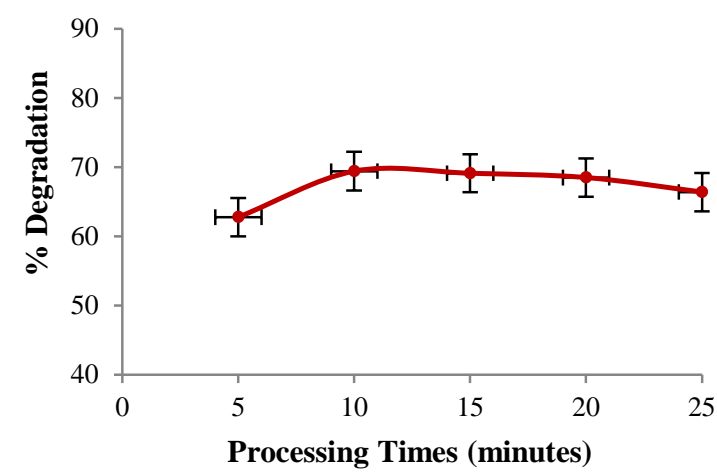

Figure 2. The effect of processing times on the degradation of imidacloprid residues in red tomatoes

\section{The effect of water volume}

Next, the effect of varying the volume of water was used to degrade imidacloprid residue in red tomatoes will be examined, with variations of $50,100,150$, and $200 \mathrm{~mL}$, weight $50 \mathrm{~g}$, and processing time 10 minutes. The degradation of imidacloprid residues is impacted by variations in water volume, as seen in Figure 3.

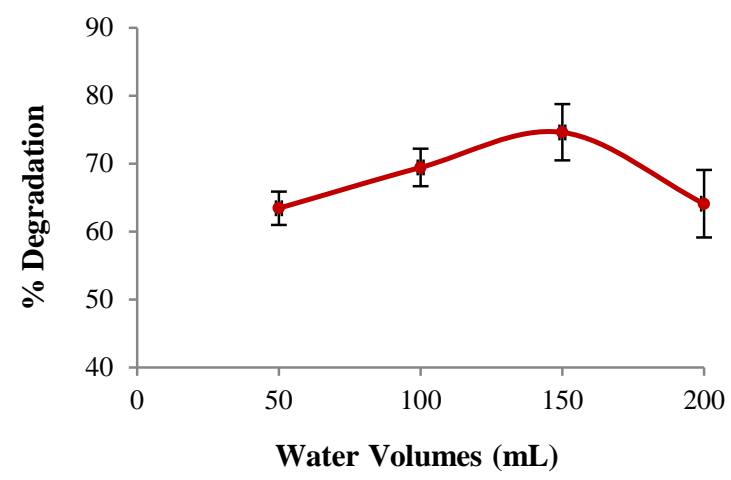

Figure 3. The effect of water volumes on the degradation of imidacloprid residues in red tomatoes

Imidacloprid residue degradation was $74.61 \%$ in red tomatoes with a volume of 150 $\mathrm{mL}$ of water and $64.10 \%$ with a volume of 200 $\mathrm{mL}$ of water. It can be seen that increasing the volume of water after obtaining the optimum condition reduces the percentage of degradation because increasing the volume of water dilutes the solution, which reduces the matrix influence on the imidacloprid residue degradation technique (Jiao et al., 2016).

\section{The effect of vegetable mass}

The percentage of pesticide residues in vegetable samples that have been degraded is also affected by the weight of the vegetables 50, 75, and 100 grams, processing time 10 minutes, and water volume $150 \mathrm{~mL}$. With the same vegetable mass of 75 grams, the highest percentage of degradation is $85.17 \%$, as shown in Figure 4. The concentration of pesticides in vegetables will rise as vegetable bulk increases. Vegetables with a large mass will exhibit a high percentage of deterioration, but the percentage of deterioration in the mass of vegetables with a big mass will decrease. This is because a high concentration causes an increase in the molar amount of pesticides bound to ozone, lowering the dissolved ozone concentration and causing a small amount of $\mathrm{OH} \bullet$ to form (Wang et al., 2019).

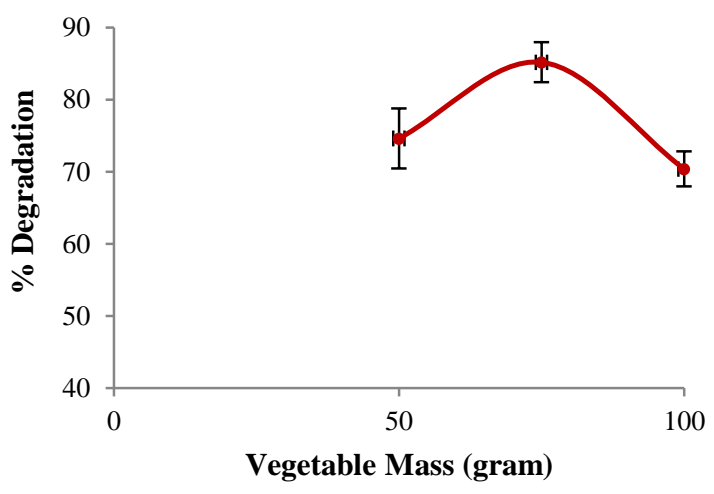

Figure 4. The effect of vegetable mass on the degradation of imidacloprid residues in red tomatoes

\section{The Effect of Soaking Time with Ozone Water}

Soaking of vegetable samples in water for $5,10,15,20$, and 25 minutes is used in this procedure. Figure 5 shows that as the period spent soaking vegetable samples in ozone water increases, the percentage of degradation increases as well. Because longer contacts of $\mathrm{OH} \cdot$ with the surface of vegetables result from extended immersion time with ozone water, the degraded effect of ozone on imidacloprid residues in vegetable samples is maximized 
(Souza et al., 2018). Furthermore, Ozonation is a chemical wastewater and water treatment method that uses ozone's oxidation potential. Ozone is a gas composed of three oxygen atoms $(\mathrm{O})$. It has a high oxidation potential and is one of the most powerful oxidants $(2.07 \mathrm{~V})$ (Güneş et al., 2021). Immersion in ozone water in the 15 minutes caused the greatest percentage of degradation, with a value of $91.65 \%$ for red tomatoes.

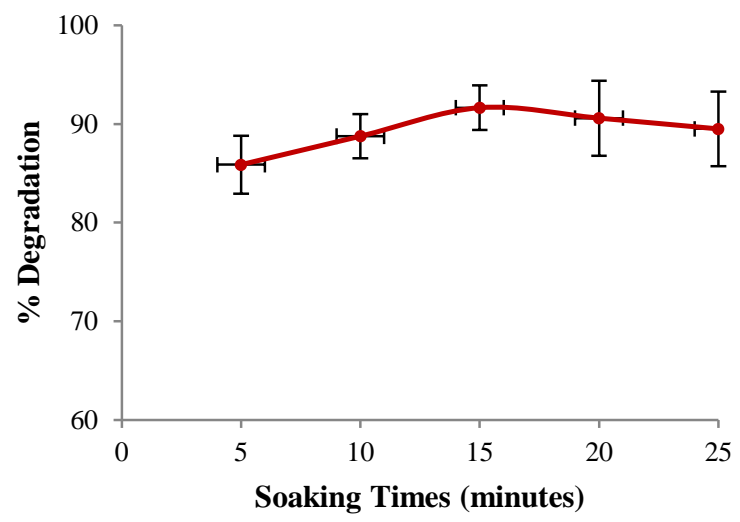

Figure 5. The effect of soaking time with ozone water on imidacloprid residue degradation in red tomatoes

\section{HPLC Analysis}

A chromatogram of imidacloprid solution, red tomatoes before and after degradation is shown in Figure 6 acetonitrile, and water $(65: 35 \mathrm{v} / \mathrm{v})$ was utilized as the mobile phase, with a flow rate of $0.8 \mathrm{~mL} / \mathrm{min}$ and a 10 $\mu \mathrm{L}$ injection volume. Because of the polarity variations between acetonitrile and other solvents such as methanol, it affects the retention time that appears on the chromatogram (Abdullah et al., 2016). The imidacloprid peaks appear at the retention time of 7.5 minutes with a peak area of 41069 , red tomatoes before degradation appears at the retention time of 7.4 minutes with a peak area of 11360 , and red tomatoes after degradation appear at the retention time of 7.4 minutes with the peak area of 2094, as shown in Figure 6. The chromatogram of the two peaks, before and after degradation, showed that the imidacloprid contained in red tomatoes had been successfully destroyed, as evidenced by a reduction in the intensity of the chromatogram peaks. It can also be verified by calculating the pesticide imidacloprid concentration in red tomatoes following a breakdown, which was determined to be $0.2 \mathrm{mg} / \mathrm{L}$.

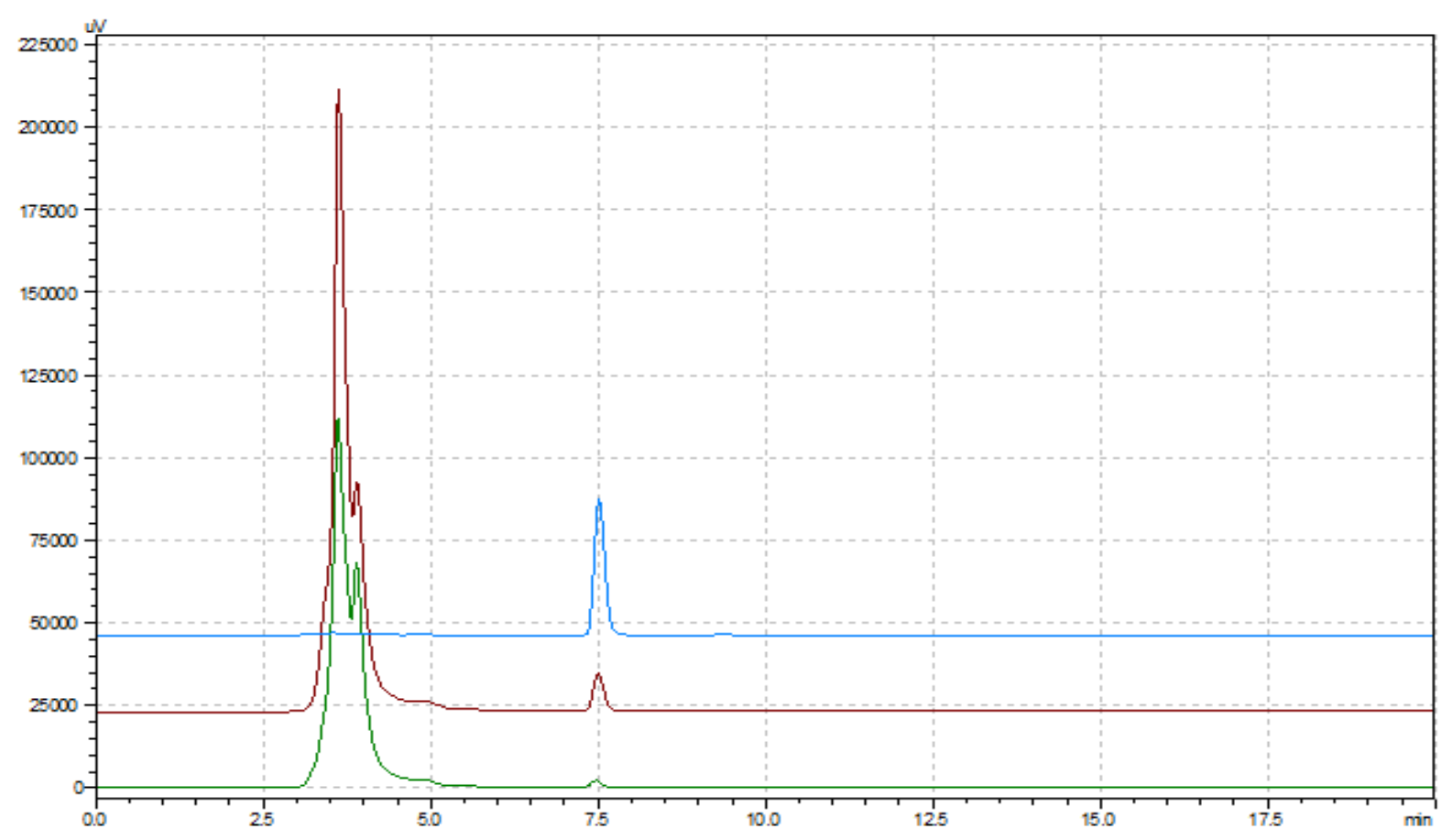

Figure 6. Chromatogram of imidacloprid solution, the solution before degradation, and the solution after degradation in red tomatoes

Information:

Imidacloprid solution

Imidacloprid in red tomatoes before degradation

Imidacloprid in red tomatoes after degradation 


\section{Kinetic of Study}

The reaction kinetics study in this study was based on the results of the highest percentage of imidacloprid residue degradation in red tomatoes, which was achieved with ozone water. The Langmuir-Hinshelwood kinetic model with a first-order reaction equation was used in this kinetic study. The graphic relation between $\ln [\mathrm{C} / \mathrm{Co}]$ can be seen in Figure 7, where [C] represents the concentration of imidacloprid residue at time $t$ and $[\mathrm{Co}]$ represents the initial concentration of imidacloprid residue. The imidacloprid residue in red tomatoes has a coefficient of determination (R2) of 0.9946 . The linearity value of those order equations shows that imidacloprid residue degradation in red tomatoes is well fitted with the first-order model as shown in Figure 7.

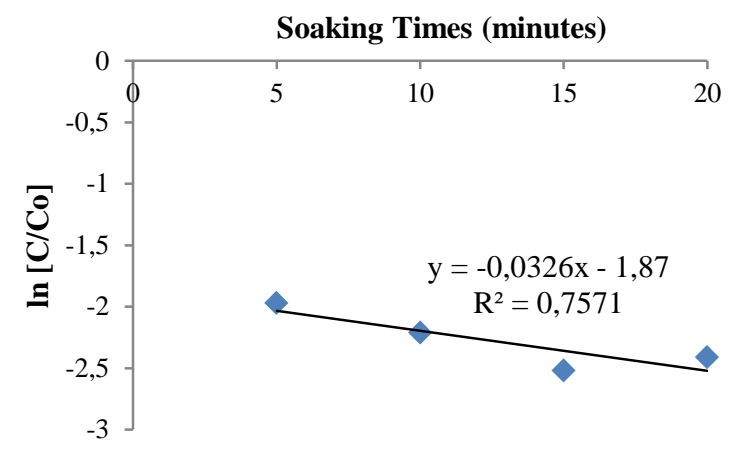

Figure 7. Relation between $[\mathrm{C} / \mathrm{Co}]$ with soaking time on imidacloprid residue degradation in red tomatoes

\section{CONCLUSION}

The imidacloprid residue in red tomatoes can be degraded $57.38 \%$ by sonozonolysis, $63.51 \%$ by sonolysis, $85.17 \%$ by ozonolysis, and $88.76 \%$ by ozone water with a processing time of 10 minutes. The imidacloprid residue on red tomatoes can be degraded by $91.65 \%$ by the ozone water soaking method for 15 minutes. The imidacloprid residue on red tomatoes was 0.2 $\mathrm{mg} / \mathrm{L}$ after degradation. Red tomatoes are safe for consumption even after they have obtained this concentration. From the National Standardization Agency's and the Minister of Health's maximum threshold value for pesticide residues in agricultural products, that is $0.5 \mathrm{mg} / \mathrm{L}$.

\section{ACKNOWLEDGMENT}

The Professorship Grant from Andalas University provided financial support for this research.

\section{REFERENCES}

Abdullah, Randhawa, M. A., Akhtar, S., MansoorUl-Hassan, Asghar, A., Sohaib, M., Aadil, R. M., \& Jahangir, M. A. (2016). Assessment of different washing treatments to mitigate imidacloprid and acetamaprid residues in spinach. Journal of the Science of Food and Agriculture, 96(11), 3749-3754. https://doi.org/10.1002/jsfa.7563

Aliasgharlou, N., Bahram, M., Zolfaghari, P., \& Mohseni, N. (2020). Modeling and optimization of simultaneous degradation of rhodamine B and acid red 14 binary solution by homogeneous Fenton reaction: A chemometrics approach. Turkish Journal of Chemistry, 44(4), 987-1001. https://doi.org/10.3906/KIM-2002-59

Dhananjayan, V., \& Ravichandran, B. (2018). Occupational health risk of farmers exposed to pesticides in agricultural activities. Current Opinion in Environmental Science and Health, 4, 3137.

https://doi.org/10.1016/j.coesh.2018.07.00 5

Gardoni, D., Vailati, A., \& Canziani, R. (2012). Decay of Ozone in Water: A Review. Ozone: Science and Engineering, 34(4), 233-242.

https://doi.org/10.1080/01919512.2012.68 6354

Güneş, E., Çİfçİ, D. İ., Dİnçer, A. R., \& Güneş, Y. (2021). Removal of $C O D$, aromaticity and color of a pretreated chemical producing industrial wastewater: a comparison between adsorption, ozonation, and advanced oxidation processes. 1-15. https://doi.org/10.3906/kim-2010-48

Han, W., Tian, Y., \& Shen, X. (2018). Human exposure to neonicotinoid insecticides and the evaluation of their potential toxicity: An overview. Chemosphere, 192, 59-65. https://doi.org/10.1016/j.chemosphere.201 7.10.149

Hao, J., Liu, H., Chen, T., Zhou, Y., Su, Y., \& Li, L. (2011). Reduction of Pesticide Residues on Fresh Vegetables with Electrolyzed 
Water Treatment. Journal of Food Science, 76(4), 3-7. https://doi.org/10.1111/j.1750-

3841.2011.02154.x

Iizuka, T., Maeda, S., \& Shimizu, A. (2013). Removal of pesticide residue in cherry tomato by hydrostatic pressure. Journal of Food Engineering, 116(4), 796 dan 800. https://doi.org/10.1016/j.jfoodeng.2013.01. 035

Ikeura, H., Kobayashi, F., \& Tamaki, M. (2011). Removal of residual pesticides in vegetables using ozone microbubbles. Journal of Hazardous Materials, 186(1), 956-959.

https://doi.org/10.1016/j.jhazmat.2010.11. 094

Jiao, W., Xiao, Y., Qian, X., Tong, M., Hu, Y., Hou, R., \& Hua, R. (2016). Optimized combination of dilution and refined QuEChERS to overcome matrix effects of six types of tea for determination eight neonicotinoid insecticides by ultra performance liquid chromatographyelectrospray tandem mass spectrometry. Food Chemistry, 210, 26-34. https://doi.org/10.1016/j.foodchem.2016.0 4.097

Lozowicka, B., \& Jankowska, M. (2016). Removal of 16 pesticide residues from strawberries by washing with tap and ozone water, ultrasonic cleaning and boiling. https://doi.org/10.1007/s10661-015-4850-6

Morrissey, C. A., Mineau, P., Devries, J. H., Sanchez-Bayo, F., Liess, M., Cavallaro, M. C., \& Liber, K. (2015). Neonicotinoid contamination of global surface waters and associated risk to aquatic invertebrates: A review. Environment International, 74, 291-303.

https://doi.org/10.1016/j.envint.2014.10.02 4

Niaz, A., Sial, R. A., Yaseen, M., Mand, G. A., Javed, M. H., Ahmad, E., Ahmad, R., \& Rahim, M. (2016). Determination of imidacloprid residues in rice from various districts of Punjab using high performance liquid chromatography. Journal of Animal and Plant Sciences, 26(1), 170-176.

Pinheiro, J., Alegria, C., Abreu, M., Sol, M., Gonçalves, E. M., \& Silva, C. L. M. (2014). (Solanum Lycopersicum, CV. Zinac) at two maturity stages following heat treatment, pp. 1-13, 2014. 1-13. https://doi.org/10.1111/jfpp.12279

Putri, R. A., Safni, S., Wellia, D. V., Septiani, U., \& Jamarun, N. (2019). Degradasi Zat Warna Orange-F3R dan Violet-3B secara Sonolisis Frekuensi Rendah dengan Penambahan Katalis C-N-Codoped TiO2. Jurnal Kimia Valensi, 5(1), 35-43. https://doi.org/10.15408/jkv.v5i1.7801

Qi, H., Huang, Q., \& Hung, Y. (2017). Department of Food Science and Technology , University of Georgia , 1109 Experiment Street ,. Food Chemistry. https://doi.org/10.1016/j.foodchem.2017.0 6.144

Safni, S., Khoiriah, K., Syukri, S., \& Gunlazuardi, J. (2020). The operational parameters effect on photocatalytic degradation of diazinon using carbon and nitrogen modified TiO2. Rasayan Journal of Chemistry, 13(3), 1919-1925. https://doi.org/10.31788/RJC.2020.133574 3

Safni, Safni, Safitri, V. Y., Santoni, A., Wellia, D. V., \& Khoiriah, K. (2017). Degradation of Paracetamol by Photolysis Using C-Ncodoped TiO2. Molekul, 12(2), 189. https://doi.org/10.20884/1.jm.2017.12.2.37 8

Safni, Safni, Wahyuni, M. R., Khoiriah, K., \& Yusuf, Y. (2019). Photodegradation of phenol using N-doped $\mathrm{TiO} 2$ catalyst. Molekul, 14(1), 6-10. https://doi.org/10.20884/1.jm.2019.14.1.44 7

Sharma, A., Kumar, V., Bhardwaj, R., \& Thukral, A. K. (2017). Seed pre-soaking with 24epibrassinolide reduces the imidacloprid pesticide residues in green pods of Brassica juncea L. Toxicological and Environmental Chemistry, 99(1), 95-103. https://doi.org/10.1080/02772248.2016.11 46955

Souza, L. P. de, Faroni, L. R. D. A., Heleno, F. F., Pinto, F. G., Queiroz, M. E. L. R. de, \& Prates, L. H. F. (2018). Ozone treatment for pesticide removal from carrots: Optimization by response surface methodology. Food Chemistry, 243, 435441.

https://doi.org/10.1016/j.foodchem.2017.0 9.134 
Wang, S., Wang, J., Wang, T., Li, C., \& Wu, Z. (2019). Effects of ozone treatment on pesticide residues in food: a review.
International Journal of Food Science and Technology, 54(2), 301-312. https://doi.org/10.1111/ijfs.13938 